ionship and perhaps witty conversation during the meal. Check every day at the Hospitality Booth for the evening's possible selections and sign up by 4:00 p.m. In this way, we hope to provide you with every opportunity to sample the joys of eating in Cincinnati and to participate in research that makes a differencel Bon appetit!
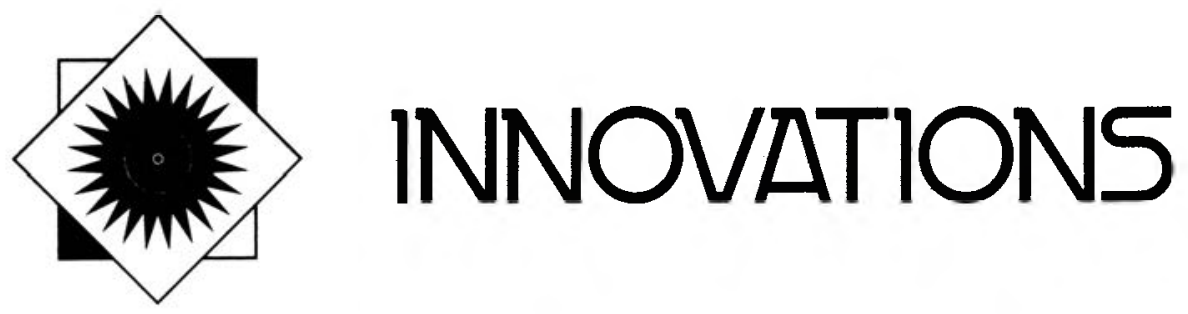

\title{
Automation orientation programs at the University of Delaware Library
}

\author{
By Carol Anne Hert \\ Senior Assistant Librarian, Systems Department \\ University of Delaware
}

Integrated online library systems (IOLS) are changing the way libraries function and how they are organized. As systems are implemented, new types of work are being created and old barriers between units are falling. Critical to the successful implementation of an integrated system is an enthusiastic staff: one not threatened by change, and able to think beyond the boundaries of current jobs to creatively assess automation's role in their work. ${ }^{1}$

The creation of this kind of spirit requires more than task-oriented training, although that is certainly an essential element of any training program. Sokol and Bulyk have outlined a three-part model of training to enable the successful implementation of new technology. ${ }^{2}$ The components are: sensitization, education, and training. Sensitization refers to training to provide the emotional preparation for new technology. It should address concerns about change such as loss of control and job security, and should build staff's confidence about their ability to master the system. Education

\footnotetext{
${ }^{1}$ Sheila D. Creth, Effective On-the-Job Training: Developing Library Human Resources (Chicago: American Library Association, 1986), 2.

Ellen W. Sokol and John C. Bulyk, "The Truth About Training," Journal of Information Systems Management 2 (Fall 1985): 75-76.
}

is the process of teaching staff to think creatively about a particular technology's possibilities and implications within the context of institutional missions. Actual task-related training to provide staff with the necessary proficiencies to employ the new technology is the final component of the Sokol and Bulyk model.

At the University of Delaware Library, the Systems Department is charged with developing training for our IOLS, NOTIS. Recognizing that taskspecific training alone would not be sufficient for the smooth implementation of the system, we developed a series of orientation programs designed to address the sensitization and education components of Sokol and Butyl's training model. We have merged these two components in our programs in the belief that they can not really be separated. A feedback loop exists, with increasing confidence about the system making education about the capabilities and potentials of the system easier, and vice versa.

The University of Delaware Library Systems Department's orientation programs are of two types: programs to teach basic system competencies, and programs focusing on general automation and system topics. Basic competency programs include introductions to the public catalog and to the technical services mode of the system. Among the 
subjects addressed during the general programs are the functioning of specific components and various other library automation topics.

The basic competency programs are hands-on sessions required of all new staff, and proficiency in using the terminal and employing the basic search keys is stressed. Our goal is to help staff develop a mastery of the rudiments of system manipulation, so that these are not stumbling blocks during jobspecific training. The first session, the introduction to the public catalog, is provided on demand by a staff person in the Systems Department. Because the online catalog of NOTIS is fairly selfexplanatory, the sessions focus on becoming familiar with the terminal and the services and personnel of the Systems Department.

The second session is to the technical services mode: how to search it, display records, and interpret the information. Staff use a self-paced workbook which guides them through an explication of the MARC record, and the structure and commands of the technical services mode. No jobspecific commands (such as how to create a record) are taught. Through these required orientation programs, staff are prepared with the tools they will need as they progress through their particular job-specific training.

The second type of orientation program is a lecture/discussion series on the system and library automation in general. These sessions are optional and are presented once a month at lunchtime. The goal of these sessions is to provide staff with an opportunity to learn about unfamiliar parts of the system and also to provide a broader view of the system in order to foster an understanding of Delaware's specific usage of NOTIS. We believe that these sessions improve the staff's ability to think positively and creatively about automation in the library. There are two types of lecture/discussion sessions: those which highlight specific components of the system or upcoming system enhancements, and those which cover more general topics such as computer technology and how the system processes information.

The sessions which focus on a component of the system are geared to those not working with the component. Because NOTIS is an integrated system, it is important for all staff to understand the inter-connectivity of the various components and this concept is stressed during the sessions. Specific library policies are not discussed as there are other forums for disseminating that information. We focus instead on how various functions are performed on the system so that people begin to comprehend the structure and operations of NOTIS. For example, in the circulation component session, when discussing the discharge function, we mention how the system actually processes a discharge and which files and records are updated during the process. In addition to the component-specific sessions, the lecture/discussion format works well for communicating information about major system enhancements.

We also run sessions which highlight more general topics. Many staff do not have a clear understanding of computers or their applications in libraries. Such an understanding will become increasingly important as the level of automation in our library rises and the sensitization and education issues of training become more obvious. Among the sessions we have offered or are planning to offer are: basic computer hardware, software, and telecommunications as they relate to our system; the role of the MARC record in library automation, particularly the use of MARC in our system; the structure of NOTIS (programs, tables, and data); and the loading and indexing of records.

At the University of Delaware Library, we have found that automation orientation programs are a critical part of a comprehensive training program for an integrated online library system. The programs can have numerous benefits for the institution. First, training costs can be reduced as staff are led logically from a basic understanding of the system to the more specific information they will need to do their job, thereby minimizing retraining. Orientation programs also provide background information that allows staff at all levels to make in formed decisions about possible applications of the system. Finally, staff begin to see change as a positive and creative opportunity. Since technological change is a given for libraries, library staff must be emotionally and intellectually prepared for such change. Developing automation orientation programs which capture the sensitization and education components of training is one method for preparing staff, and one which has been successful at the University of Delaware Library.

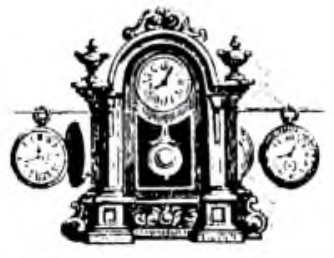

\section{Model Statement of Objectives for Academic Bibliographic Instruction}

The "Model Statement of Objectives for Academic Bibliographic Instruction" developed by the BIS Task Force on the Model Statement was approved by the ACRL Board of Directors and the ALA Standards Committee during the 1988 Annual Conference in New Orleans.

As approved, the statement is the same as the final draft that appeared in C\&RL News, May 1987, pp.256-61. 